\title{
Plutonium Immobilization Can Loading Concepts
}

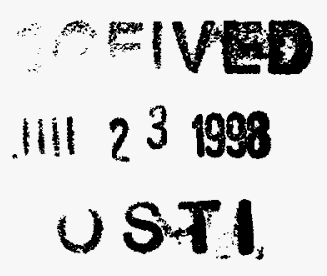

by

E. Kriikku

Westinghouse Savannah River Company

Savannah River Site

Aiken, South Carolina 29808

C. Ward

L. Hamilton

M. Stokes

L. Rogers

B. Randall

J. Fiscus

J. Steed

G. Dyches

R. Jones

\section{MASTER $\boldsymbol{\gamma}^{\mu}$}

DISTRIBUTON OF THAS DOCUMENT IS UAHMATED

DOE Contract No. DE-AC09-96SR18500

This paper was prepared in connection with work done under the above contract number with the U. S.

Department of Energy. By acceptance of this paper, the publisher and/or recipient acknowledges the U. S. Government's right to retain a nonexclusive, royalty-free license in and to any copyright covering this paper, along with the right to reproduce and to authorize others to reproduce all or part of the copyrighted paper. 


\section{DISCLAIMER}

This report was prepared as an account of work sponsored by an agency of the United States Government. Neither the United States Government nor any agency thereof, nor any of their employees, makes any warranty, express or implied, or assumes any legal liability or responsibility for the accuracy, completeness, or usefulness of any information, apparatus, product, or process disclosed, or represents that its use would not infringe privately owned rights. Reference herein to any specific commercial product, process, or service by trade name, trademark, manufacturer, or otherwise does not necessarily constitute or imply its endorsement, recommendation, or favoring by the United States Government or any agency thereof. The views and opinions of authors expressed herein do not necessarily state or reflect those of the United States Government or any agency thereof.

This report has been reproduced directly from the best available copy.

Available to DOE and DOE contractors from the Office of Scientific and Technical Information, P. O. Box 62, Oak Ridge, TN 37831; prices available from (423) 576-8401.

Available to the public from the National Technical Information Service, U. S. Department of Commerce, 5285 Port Royal Road, Springfield, VA 22161. 


\section{DISCLAIMER}

Portions of this document may be illegible electronic image products. Images are produced from the best available original document. 
WSRC-TR-98-00165

\section{Plutonium Immobilization Preliminary Can Loading Concepts (U)}

May 29, 1998

Westinghouse Savannah River Company Savannah River Site Aiken, SC 29808 


\title{
Plutonium Immobilization Preliminary Can Loading Concepts (U)
}

The following Plutonium Immobilization Can Loading Team members contributed to this report.

\author{
Bill Randall \\ NMS\&S \\ Jim Steed \\ NMS\&S \\ Robert Jones \\ NMS\&S \\ Clyde Ward \\ SRTC/EES \\ Mitchell Stokes \\ SRTC/EES \\ Lane Rogers \\ SRTC/EES \\ Lee Hamilton \\ SRTC/EES \\ Greg Dyches \\ SRTC/EES \\ James Fiscus \\ SRTC/EES \\ Eric Kriikku \\ SRTC/EES
}




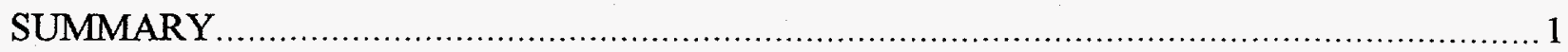

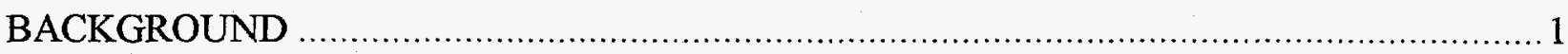

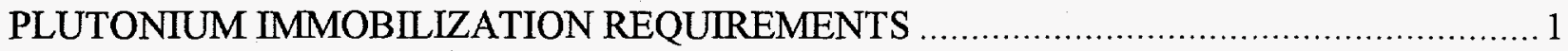

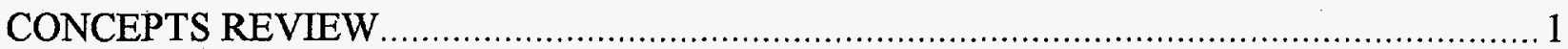

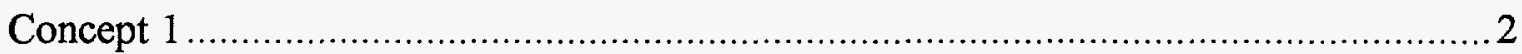

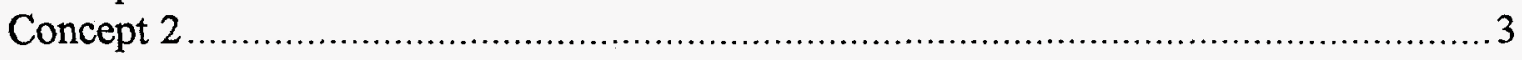

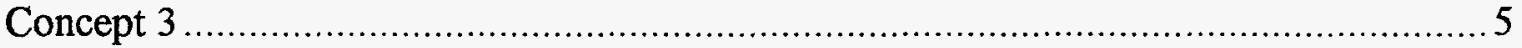

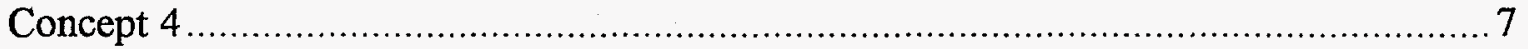

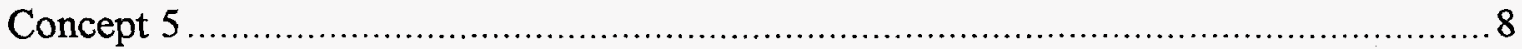

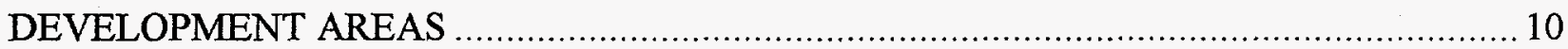

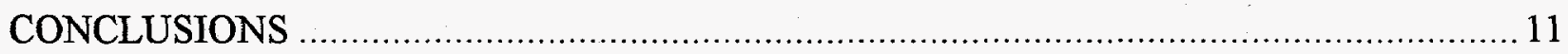




\section{SUMMARY}

The Plutonium Immobilization Facility will encapsulate plutonium in ceramic pucks and seal the pucks inside welded cans. Remote equipment will place these cans in magazines and the magazines in a Defense Waste Processing Facility (DWPF) canister. The DWPF will fill the canister with glass for permanent storage. This report discusses five can loading conceptual designs and the lists the advantages and disadvantages for each concept. This report identifies loading pucks into cans and backfilling cans with helium as the top priority can loading development areas. The can loading welder and cutter are very similar to the existing Savannah River Site (SRS) FB-Line bagless transfer welder and cutter and thus they are a low priority development item.

\section{BACKGROUND}

The Plutonium Immobilization Facility design will minimize operator exposure and prevent the spread of contamination. To accomplish these goals, a system must package contaminated materials in clean containers and not release contamination. Traditional methods of removing plutonium from process gloveboxes in preparation for packaging involves the use of bagout procedures utilizing plastic bags. This method is not acceptable in the Plutonium Immobilization Facility. Engineers at the SRS developed a system for removing plutonium from a glovebox directly into an all metal, welded, leaktight container, free of external contamination. The process, known as bagless transfer, utilizes a Tungsten-Inert-Gas (TIG) welding process to seal plutonium in a can. The process then separates the transfer can from the glovebox environment while maintaining glovebox and can integrity. A semi-automated bagless transfer unit is in operation at the Savannah River Site FB-Line Plutonium Facility. The Plutonium Immobilization Can Loading operations will use this system as a baseline.

\section{PLUTONIUM IMMOBILIZATION REQUIREMENTS}

The Plutonium Immobilization facility must produce approximately 560 pucks per day to meet production requirements. The can loading system must be able to automatically load at least 24 pucks per hour into puck cans. Remote equipment will load the puck cans into magazines and load the magazines into racks inside the DWPF canisters. The DWPF fills canisters with approximately 91 inches of glass and the glass must surround the puck cans, magazines, and racks.

Normal can loading system operations will be performed remotely, but maintenance and repairs will be performed manually. The can loading system shall minimize the amount of equipment in the containment, minimize the complexity of the equipment in the containment, design the equipment for minimal maintenance, and design the equipment for glovebox repair and replacement.

\section{CONCEPTS REVIEW}

The following sections describe five can loading concepts and the advantages and disadvantages of each. 


\section{Concept 1}

Figure 1 shows a side view of Can Loading Concept 1. A tray of pucks enters the loading glovebox on a magnetic linear transport cart, and the tray staging system lifts the tray from the cart. The cart moves the empty tray from the tray staging system to the elevator. The puck robot (SCARA type) removes the pucks from the tray and loads them into the can. The system seals the loading glovebox, removes the atmosphere, and introduces helium to ensure the puck can contains helium. The puck robot places a plug into the can, the bagless transfer system welds the plug to the can wall, and cuts the can leaving the can stub in the sphincter seal. The bagless transfer system lowers the can and the can robot swipes approximately $80 \%$ of the can exterior. The can robot loads the swipe in a radiation counter and seals the counter. After the counting is complete, the can robot removes the can from the bagless transfer can holder, places it in the helium bell jar leak detector to ensure the weld is leak tight, and seals the detector. After the counting is complete, the can robot places the can on a magnetic linear transport system and the can leaves the bagless transfer glovebox.

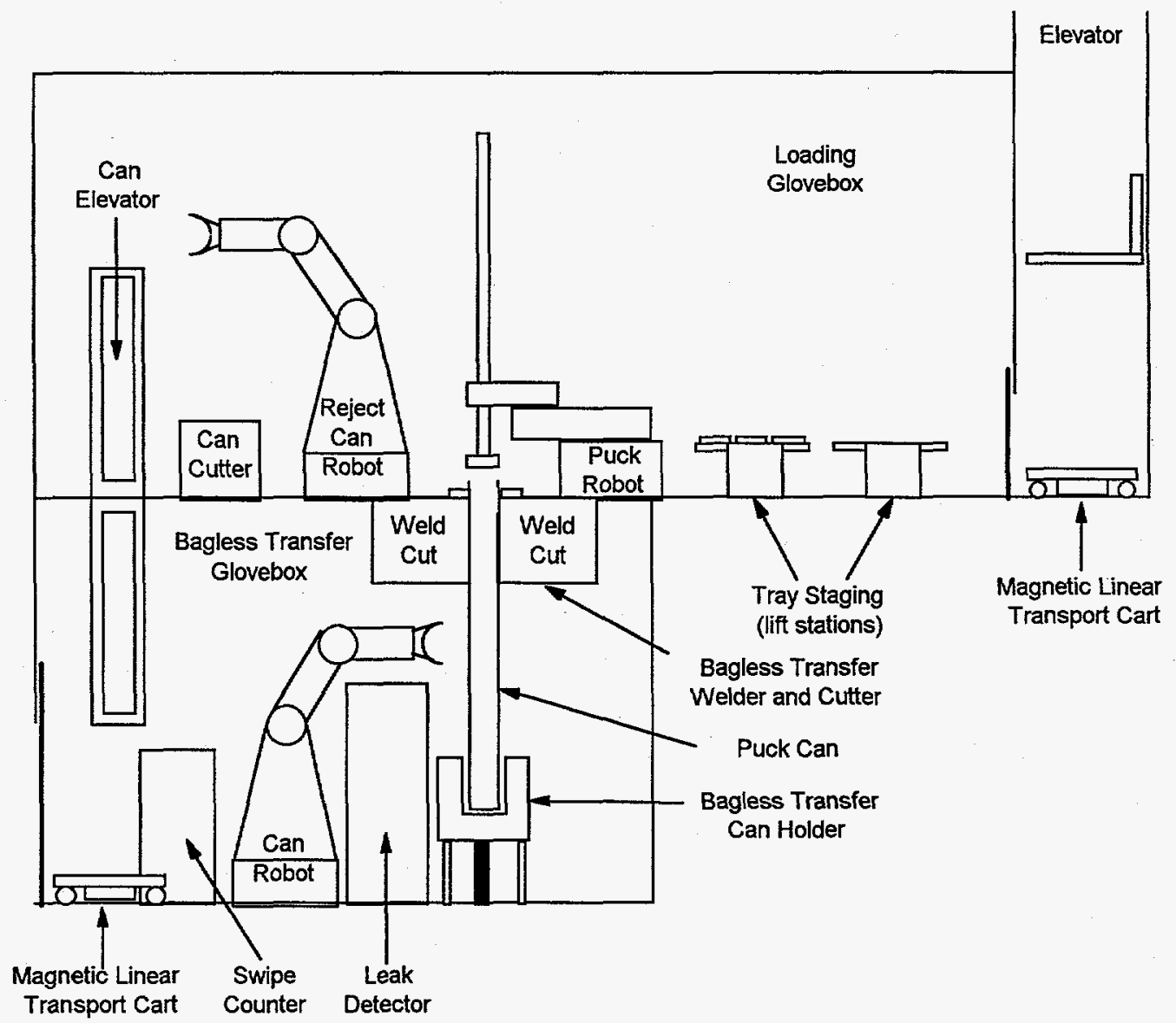

Figure 1 - Can Loading Concept 1

The new cans are manually pre-loaded with plugs, several cans are placed in a basket, and the magnetic linear transport cart brings the basket of cans to the bagless transfer glovebox. The can robot removes the basket of cans from the cart, places a new can in the bagless transfer can holder, and the bagless transfer system raises the can. The previous can stub is pushed by the new 
can into the loading glovebox and the puck robot places the stub on an empty tray. The empty tray and can stub leave the loading glovebox on the magnetic linear transport cart and the stub is taken to the waste glovebox. The puck robot removes the plug from the new can and begins loading pucks into the can.

The bagless transfer machine will push cans that experience weld failures up into the sphincter seal. The can robot will load a new can into the bagless transfer can holder and the bagless transfer system will push the new can into the sphincter seal pushing the failed can into the loading glovebox. The reject can robot will remove the can from the sphincter seal and place it in a shielded box. All pucks and loaded cans will be removed from the loading and bagless transfer gloveboxes. Operators will replace the sphincter seal and perform any system maintenance. The reject can robot will move the damaged can from the shielded box to the can cutter. The cutter will open the can, the reject can robot will place the pucks in the puck robot work envelope, the reject can robot will place cut can parts in a basket. The puck robot will load the pucks into the next can and the basket will be transported to an empty tray at the tray staging system.

The can robot will place cans that fail the swipe or leak check in the can elevator and close the elevator door. The elevator will act as an airlock between the bagless transfer glovebox and the loading glovebox to prevent the spread of contamination. The can elevator will raise the can up to the loading glovebox, the reject can robot will open the can elevator door, and remove the can from the elevator. The reject can robot will process these reject cans in a similar manner as the weld failure cans described above.

The following are advantages to concept 1 :

- The SCARA robot is designed to place items in tight places with built in compliance and is ideal to place pucks in the can.

The following are disadvantages to concept 1 :

- The concept uses three robots, other concepts use two.

- A SCARA robot with 30 inch plus vertical travel is not commercially available

- A SCARA robot has trouble holding a tool that has 30 inch stroke. SCARA robots are not designed to carry large or moment creating loads.

- A SCARA robot can't transport waste from reject can robot to trays so extra equipment is needed for this task.

- The concept fills the puck cans with helium by introducing helium in the loading glovebox. This method must be tested.

\section{Concept 2}

Figure 2 shows a side view of Can Loading Concept 2. A tray of pucks enters the loading glovebox on a magnetic linear transport cart and the tray staging system lifts the tray from the cart. The cart moves the empty tray from the tray staging system to the elevator. The puck robot (jointed arm type) removes the pucks from the tray and places them under the pick and place machine. The pick and place machine loads the pucks in the can. The loading glovebox is sealed, the atmosphere is removed, and helium is introduced to ensure the puck can contains helium. The puck robot places a plug under the pick and place machine and the pick and place machine places the plug in the can, the bagless transfer system welds the plug to the can wall, and cuts the can leaving the can stub in the sphincter seal. The bagless transfer system lowers the can and the can 
robot swipes approximately $80 \%$ of the can exterior. The can robot loads the swipe in a radiation counter and seals the counter. After the counting is complete, the can robot removes the can from the bagless transfer can holder, places it in the helium bell jar leak detector to ensure the weld is leak tight, and seals the detector. After the counting is complete, the can robot places the can on a magnetic linear transport system and the can leaves the bagless transfer glovebox.

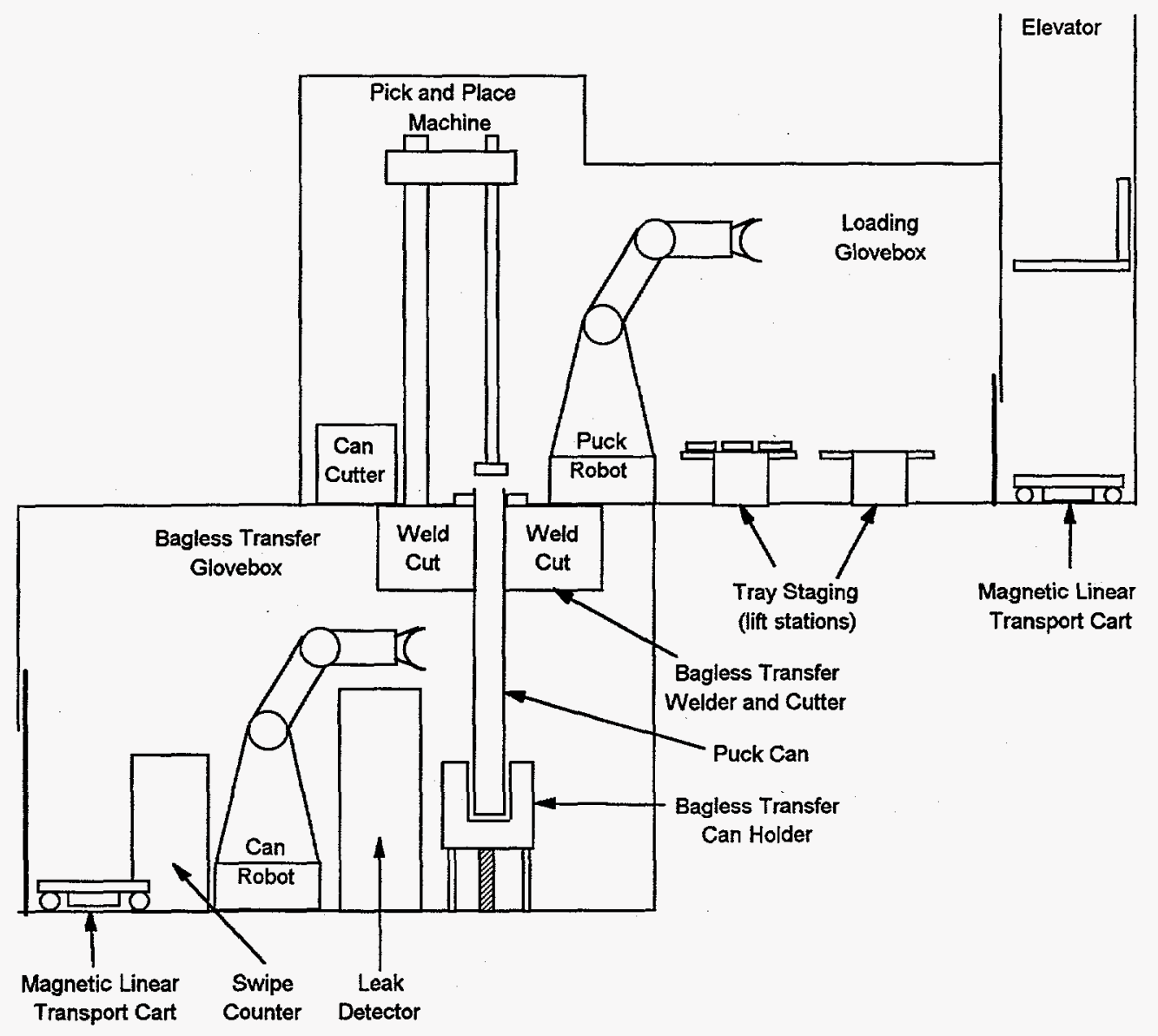

Figure 2 - Can Loading Concept 2

The new cans are manually pre-loaded with plugs, several cans are placed in a basket, and the magnetic linear transport cart brings the basket of cans to the bagless transfer glovebox. The can robot removes the basket of cans, places a new can in the bagless transfer can holder, and the bagless transfer system raises the can. The previous can stub is pushed by the new can into the loading glovebox and the puck robot places the stub on an empty tray. The empty tray and can stub leave the loading glovebox on the magnetic linear transport cart and the stub is taken to the waste glovebox. The pick and place machine removes the plug from the new can, the puck robot places the plug aside, and the loading process resumes.

The bagless transfer machine will push cans that experience weld failures up into the sphincter seal. The can robot will load a new can into the bagless transfer can holder and the bagless transfer system will push the new can into the sphincter seal pushing the failed can into the loading glovebox. The puck robot will remove the failed can from the sphincter seal and place it in a shielded box. All pucks and loaded cans will be removed from the loading and bagless 
transfer gloveboxes. Operators will replace the sphincter seal and perform any system maintenance. The puck robot will move the damaged can from the shielded box to the can cutter. The cutter will open the can, the puck robot will place the pucks on a tray, the puck robot will place cut can parts in a basket. The basket will be placed on an empty tray at the tray staging system and transported to the waste processing glovebox.

The can robot will place cans that fail the swipe or leak check in the bagless transfer can holder. The bagless transfer machine will push the failed can up into the sphincter seal and this will push the stub into the loading glovebox. The puck robot will place the stub in a basket and the can robot will load a new can into the bagless transfer can holder. The bagless transfer system will push the new can into the sphincter seal pushing the failed can into the loading glovebox. The puck robot will process these reject cans in a similar manner as the weld failure cans described above.

The following are advantages to concept 2 :

- The pick and place machine is very reliable.

- The pick and place machine is well suited to perform puck loading operations.

The following are disadvantages to concept 2 :

- The concept uses two robots and a pick and place machine, instead of two robots used in other concepts.

- The concept fills the puck cans with helium by introducing helium in the loading glovebox. This method must be tested.

\section{Concept 3}

Figure 3 shows a side view of Can Loading Concept 3. A tray of pucks enters the loading glovebox on the tray indexing system. The tray indexing system can move the tray in two dimensions, $\mathrm{X}$ and $\mathrm{Y}$. The $\mathrm{X}$ dimension is from the elevator to the pick and place machine and the $\mathrm{Y}$ dimension is from side to side on the glovebox floor. The pick and place machine removes a puck from the tray and places it in the can. The tray indexing system moves the tray so the next puck is under the pick and place machine and the pick and place loads the next puck. Once the puck can is filled, the loading glovebox is sealed, the atmosphere is removed, and helium is introduced to ensure the puck can contains helium. The reject can robot places a plug under the pick and place machine and the pick and place machine places the plug in the can, the bagless transfer system welds the plug to the can wall, and cuts the can leaving the can stub in the sphincter seal. The bagless transfer system lowers the can and the can robot swipes approximately $80 \%$ of the can exterior. The can robot loads the swipe in a radiation counter and seals the counter. After the counting is complete, the can robot removes the can from the bagless transfer can holder, places it in the helium bell jar leak detector to ensure the weld is leak tight, and seals the detector. After the counting is complete, the can robot places the can on a magnetic linear transport system and the can leaves the bagless transfer glovebox.

The new cans are manually pre-loaded with plugs, several cans are placed in a basket, and the magnetic linear transport cart brings the basket of cans to the bagless transfer glovebox. The can robot removes the basket of cans, places a new can in the bagless transfer can holder, and the bagless transfer system raises the can. The previous can stub is pushed by the new can into the loading glovebox and the reject can robot places the stub on an empty tray. The empty tray and 
can stub leave the loading glovebox on the tray indexing system and the stub is taken to the waste glovebox. The pick and place machine removes the plug from the new can, the reject can robot places the plug aside, and the loading process resumes.

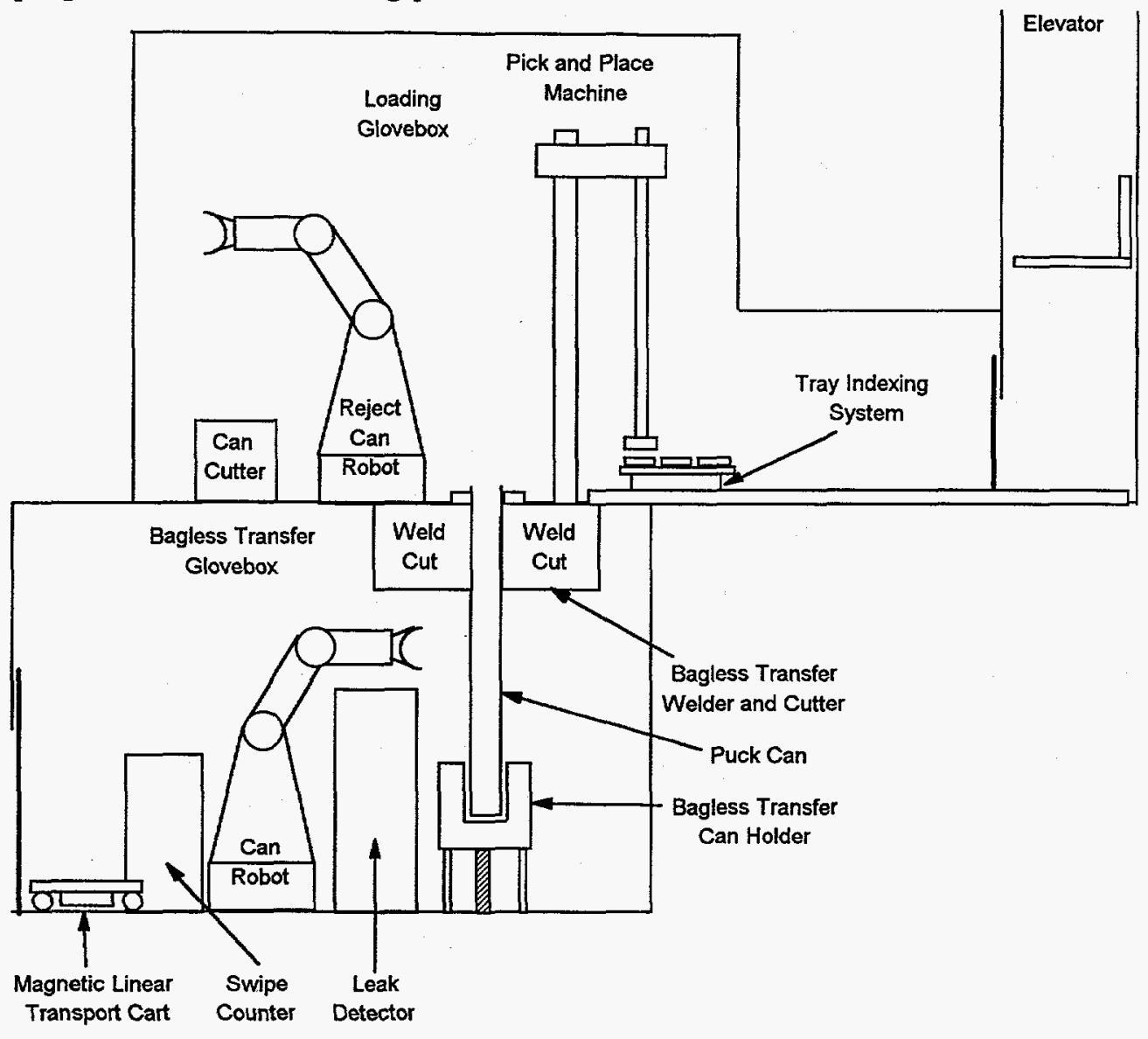

Figure 3 - Can Loading Concept 3

The bagless transfer machine will push cans that experience weld failures up into the sphincter seal. The can robot will load a new can into the bagless transfer can holder and the bagless transfer system will push the new can into the sphincter seal pushing the failed can into the loading glovebox. The reject can robot will remove the failed can from the sphincter seal and place it in a shielded box. All pucks and loaded cans will be removed from the loading and bagless transfer gloveboxes. Operators will replace the sphincter seal and perform any system maintenance. The puck robot will move the damaged can from the shielded box to the can cutter. The cutter will open the can, the puck robot will place the pucks on a tray, the reject can robot will place cut can parts in a basket. The basket will be placed on an empty tray at the tray staging system and transported to the waste processing glovebox.

The can robot will place cans that fail the swipe or leak check in the bagless transfer can holder. The bagless transfer machine will push the failed can up into the sphincter seal and this will push the stub into the loading glovebox. The reject can robot will place the stub in a basket and the can robot will load a new can into the bagless transfer can holder. The bagless transfer system will push the new can into the sphincter seal pushing the failed can into the loading glovebox. The 
reject can robot will process these reject cans in a similar manner as the weld failure cans described above.

The following are advantages to concept 3 :

- The pick and place machine is very reliable.

- The pick and place machine is well suited to perform puck loading operations.

The following are advantages to concept 3 :

- The concept uses two robots, a pick and place machine, and a tray indexing system, instead of two robots like other concepts.

- The concept fills the puck cans with helium by introducing helium in the loading glovebox. This method must be tested.

\section{Concept 4}

Figure 4 shows a side view of Can Loading Concept 4. A tray of pucks enters the loading glovebox on a magnetic linear transport cart and the tray staging system lifts the tray from the cart. The cart moves the empty tray from the tray staging system to the elevator. The puck robot (jointed arm type) removes the pucks from the tray and loads the pucks in the can. The loading glovebox is sealed, the atmosphere is removed, and helium is introduced to ensure the puck can contains helium. The puck robot places a plug in the can, the bagless transfer system welds the plug to the can wall, and cuts the can leaving the can stub in the sphincter seal. The bagless transfer system lowers the can and the can robot swipes approximately $80 \%$ of the can exterior. The can robot loads the swipe in a radiation counter and seals the counter. After the counting is complete, the can robot removes the can from the bagless transfer can holder, places it in the helium bell jar leak detector to ensure the weld is leak tight, and seals the detector. After the counting is complete, the can robot places the can on a magnetic linear transport system and the can leaves the bagless transfer glovebox.

The new cans are manually pre-loaded with plugs, several cans are placed in a basket, and the magnetic linear transport cart brings the basket of cans to the bagless transfer glovebox. The can robot removes the basket of cans, places a new can in the bagless transfer can holder, and the bagless transfer system raises the can. The previous can stub is pushed by the new can into the loading glovebox and the puck robot places the stub on an empty tray. The empty tray and can stub leave the loading glovebox on the magnetic linear transport cart and the stub is taken to the waste glovebox. The puck robot removes the plug from the new can and the loading process resumes.

The bagless transfer machine will push cans that experience weld failures up into the sphincter seal. The can robot will load a new can into the bagless transfer can holder and the bagless transfer system will push the new can into the sphincter seal pushing the failed can into the loading glovebox. The puck robot will remove the failed can from the sphincter seal and place it in a shielded box. All pucks and loaded cans will be removed from the loading and bagless transfer gloveboxes. Operators will replace the sphincter seal and perform any system maintenance. The puck robot will move the damaged can from the shielded box to the can cutter. The can cutter will open the can and the puck robot will load the pucks in the next can. The puck robot will place cut can parts in a basket and place the basket on an empty tray at the tray staging system. This waste will be sent to the waste processing glovebox. 
The can robot will place cans that fail the swipe or leak check in the bagless transfer can holder. The bagless transfer machine will push the failed can up into the sphincter seal and this will push the stub into the loading glovebox. The puck robot will place the stub in a basket and the can robot will load a new can into the bagless transfer can holder. The bagless transfer system will push the new can into the sphincter seal pushing the failed can into the loading glovebox. The puck robot will process these reject cans in a similar manner as the weld failure cans described above.

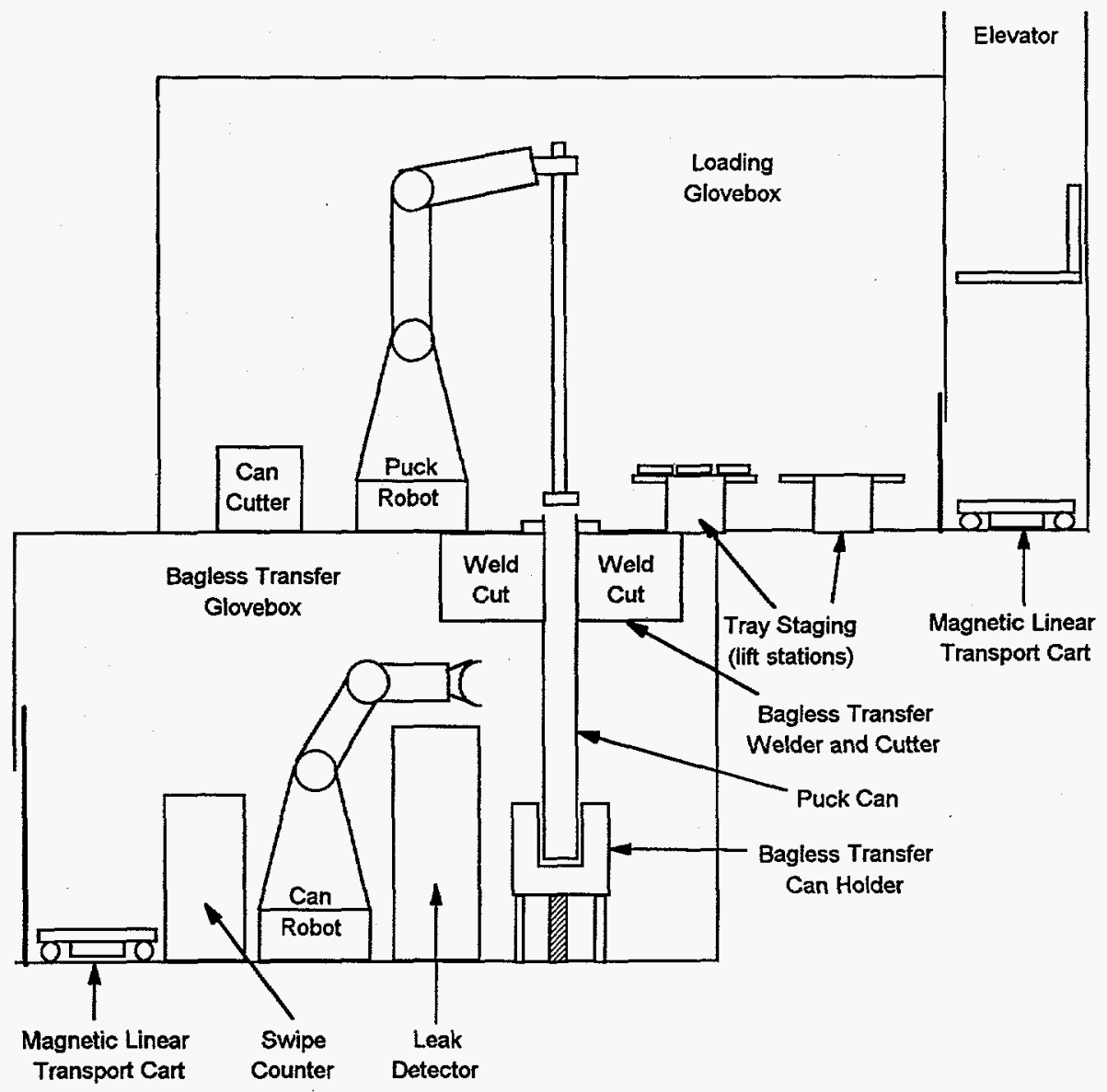

Figure 4 - Can Loading Concept 4

The following are advantages to concept 4 :

- The concept uses two robots instead of three robots like other concepts.

The following are disadvantages to concept 4 :

- The puck robot will be large and heavy for a glovebox, compared to the reject can robot.

- The concept fills the puck cans with helium by introducing helium in the loading glovebox. This method must be tested.

\section{Concept 5}

Figure 5 shows a side view of Can Loading Concept 5. A tray of pucks enters the loading glovebox on a magnetic linear transport cart and the tray staging system lifts the tray from the 
cart. The cart moves the empty tray from the tray staging system to the elevator. The puck robot (gantry type) removes the pucks from the tray and loads the pucks in the can. The puck robot places the helium hood over the can plug and the helium hood grabs the can plug. The can plug entered the loading glovebox with the puck can, see below. The puck robot places the helium hood over the puck can and the helium hood seals to the can. The helium hood removes the air from the can, fills the can with helium, and inserts the plug into the can. The bagless transfer system welds the plug to the can wall, and cuts the can leaving the can stub in the sphincter seal. The bagless transfer system lowers the can and the can robot swipes approximately $80 \%$ of the can exterior. The can robot loads the swipe in a radiation counter and seals the counter. After the counting is complete, the can robot removes the can from the bagless transfer can holder, places it in the helium bell jar leak detector to ensure the weld is leak tight, and seals the detector. After the counting is complete, the can robot places the can on a magnetic linear transport system and the can leaves the bagless transfer glovebox.

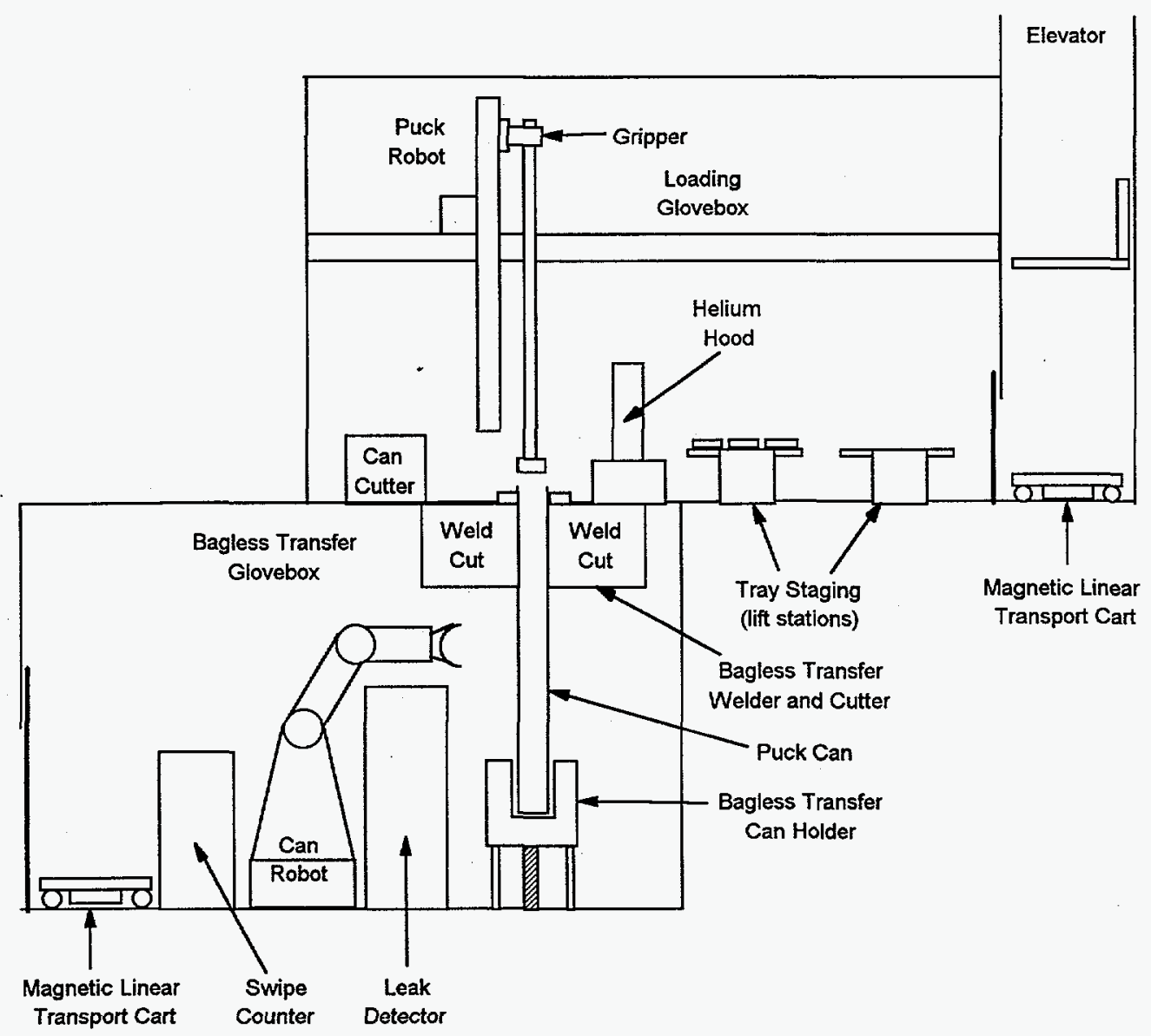

Figure 5 - Can Loading Concept 5

The new cans are manually pre-loaded with plugs, several cans are placed in a basket, and the magnetic linear transport cart brings the basket of cans to the bagless transfer glovebox. The can robot removes the basket of cans, places a new can in the bagless transfer can holder, and the bagless transfer system raises the can. The previous can stub is pushed by the new can into the loading glovebox and the puck robot places the stub on an empty tray. The empty tray and can stub leave the loading glovebox on the magnetic linear transport cart and the stub is taken to the 
waste glovebox. The puck robot removes the plug from the new can and the loading process resumes.

The bagless transfer machine will push cans that experience weld failures up into the sphincter seal. The can robot will load a new can into the bagless transfer can holder and the bagless transfer system will push the new can into the sphincter seal pushing the failed can into the loading glovebox. The puck robot will remove the failed can from the sphincter seal and place it in a shielded box. All pucks and loaded cans will be removed from the loading and bagless transfer gloveboxes. Operators will replace the sphincter seal and perform any system maintenance. The puck robot will move the damaged can from the shielded box to the can cutter. The can cutter will open the can and the puck robot will load the pucks in the next can. The puck robot will place cut can parts in a basket and place the basket on an empty tray at the tray staging system. This waste will be sent to the waste processing glovebox:

The can robot will place cans that fail the swipe or leak check in the bagless transfer can holder. The bagless transfer machine will push the failed can up into the sphincter seal and this will push the stub into the loading glovebox. The puck robot will place the stub in a basket and the can robot will load a new can into the bagless transfer can holder. The bagless transfer system will push the new can into the sphincter seal pushing the failed can into the loading glovebox. The puck robot will process these reject cans in a similar manner as the weld failure cans described above.

The following are advantages to concept 5 :

- The concept uses two robots, instead of three.

- The concept uses the lightest robot to load pucks in a can. This will facilitate maintenance and replacement.

- The concept uses a helium hood to fill cans with helium. The current bagless transfer system in SRS FB-Line uses a similar system.

The following are disadvantages to concept 5 :

- The gantry robot must be disassembled before it can be removed from the glovebox.

\section{DEVELOPMENT AREAS}

The following issues require further development to ensure a successful $\mathrm{Pu}$ Immobilization can loading system.

High Priority

1. Load pucks in cans

2. Fill can with helium and insert plug

3. Tray staging system

4. Handling pucks from reject cans

5. Handle full cans (load bagless transfer, leak detector, etc.)
Low Priority

1. Modify current bagless transfer design

2. Can swiping

3. Helium bell jar

4. Cut open reject cans

5. Handle waste (stubs, reject cans) 


\section{CONCLUSIONS}

This report discusses five possible Plutonium Immobilization Can Loading concepts. Concept 1 uses a SCARA type robot to load pucks in a can, but a SCARA robot with a 30 inch vertical travel is not commercially available. Concept 2 uses a pick and place machine to load pucks in a can. Pick and place machines are reliable, but the concept uses two robots and the pick and place machine to load cans and handle reject cans. Concept 3 uses a tray indexing system and a pick and place machine to load pucks in a can. The concept can load pucks efficiently, but it requires two robots, a pick and place machine, and a tray indexing system to load cans and handle reject cans. Concept 4 uses a jointed arm robot to load pucks in a can, but this robot will be large and heavy $(300-600 \mathrm{lbs}$.) for glovebox use. Concept 5 uses a gantry robot to load pucks in a can. This concept only uses two robots to load cans and handle reject cans, but it must be proven that the gantry robot can successfully load pucks in a can. Concept 5 is the only concept that uses a small hood to evacuate the can and fill it with helium. The other concepts maintain a helium atmosphere in the glovebox to fill the can with helium. The helium hood method could be used in any of the concepts. The concepts discussed in this report need to be reviewed and ranked. Elements from the top ranking concept need to be tested to ensure a successful conceptual design. 